\title{
The effect of increasing levels of dietary fish oil rich in eicosapentaenoic and docosahexaenoic acids on lymphocyte phospholipid fatty acid composition and cell-mediated immunity in the mouse
}

\author{
BY ALISON HINDS AND T. A. B. SANDERS \\ Department of Nutrition and Dietetics, King's College London, Campden Hill Road, \\ London $W 87 A H$
}

(Received 11 October 1991-Accepted 12 March 1992)

\begin{abstract}
The influence of increasing intakes of fish oil on spleen leucocyte phospholipid fatty acid composition and cell-mediated immunity was studied in the mouse using a popliteal lymph node assay technique. The immune response was suppressed by $160 \mathrm{~g}$ fish oil $/ \mathrm{kg}$ diet, but not by lower doses. The proportion of 20:5n-3 in spleen leucocyte phospholipid increased from 0.14 in the controls to $3.8,7 \cdot 2,8.5$ and $9.4 \%$ in the animals fed on $25,50,100$ and $160 \mathrm{~g}$ fish oil $/ \mathrm{kg}$ diet; the proportion of $22: 6 n-3$ increased from $5 \cdot 1$ in the controls to $12 \cdot 1,12 \cdot 2,12 \cdot 8$ and $12.9 \%$ respectively. It is concluded that moderate intakes of fish oil are not immunosuppressive.
\end{abstract}

Immune function: Polyunsaturated fatty acids: Lymphocytes: Fish oil

Eicosanoid derivatives of the essential fatty acids (EFA) are believed to play an important role in the regulation of the immune system. Cell-mediated immunity (CMI) is impaired in EFA deficiency and the severity of several autoimmune disorders is ameliorated by low intakes of linoleic acid $(18: 2 n-6)$ coupled with high intakes of fish oil rich in eicosapentaenoic acid (20:5n-3; EPA) and docosahexaenoic acid (22:6n-3; DHA) (Sanders, 1988).

CMI is mediated by T-lymphocytes and depends on the interaction of antigens with specific surface receptors on the T-cells. Various sub-populations of T-cells have different roles when activated by antigens. T-helper cells enable a response to be elicited for T-cytotoxic cells on initial exposure to an antigen. When activated these cause lysis of target cells bearing antigens. T-suppressor cells inhibit $\mathrm{T}$-helper cell activity and are, therefore, capable of regulating the immune response. T-cell hypersens release biologically active lymphokines which recruit and activate the phagocytic cells of the non-specific immune system.

The CMI response is characterized by a delayed reaction, often $24 \mathrm{~h}$ after challenge with antigens. The response occurs most effectively in secondary lymphoid tissues such as spleen and lymph nodes, which are the sites of lymphocyte proliferation and activation. It is possible to investigate CMI using transplantation of grafts from a donor to a host animal. Where genetic differences exist between the donor and host, the graft is recognized as being a foreign antigen and, in conjunction with macrophages, activates $T$-cells. These either release lymphokines or transform into killer $\mathrm{T}$-cells and mediate rejection of the graft tissue. This is known as the Host $v$. Graft $(\mathrm{H} v . \mathrm{G})$ response.

The present study reports the effect on CMI of increasing intakes of EPA and DHA while keeping linoleic and saturated fatty acid intakes constant, using the mouse popliteal lymph 
node assay. This H v. G model (Twist \& Barnes, 1973) involves subcutaneous footpad injection of graft cells, which induces a CMI reaction in the popliteal lymph nodes located in the hind legs of the animal. Lymph nodes act as filters for lymph draining the body tissues and are responsible for circulation of lymphocytes between the blood stream, tissues and lymph glands. The size of the popliteal lymph node reaches its maximum approximately $4 \mathrm{~d}$ after injection of donor spleen cells (Twist \& Barnes, 1973). Enlargement is caused mainly by an increase in node cellularity due to $\mathrm{T}$ and $\mathrm{B}$ lymphocyte proliferation, and to a lesser extent by accumulation of cells circulating through the lymphoid tissue (Rolstad, 1976). The extent of lymph node swelling is proportional to the number of allogeneic or parental strain donor cells injected (Mertin \& Stackpoole, 1983). An abstract of the present study has been published previously (Hinds \& Sanders, 1986).

\section{METHODS}

Forty male 5-week-old CBA $\times$ CBA mice (approximately $15 \mathrm{~g}$, Harlan Olac, Bicester, Oxon) were randomly allocated to five experimental groups (eight animals per group) individually caged and fed on a semi-purified diet for 4 weeks. All the ingredients of the diet were prepared in one batch and stored in a sealed bag under $\mathrm{N}_{2}$ at $4^{\circ}$ and the oil blends were prepared and added to the mixture on a weekly basis to minimize autooxidation. Food intake was restricted to $5 \mathrm{~g} / \mathrm{mouse}$ per $\mathrm{d}$ and the wastage and spillage recorded twice weekly in order to determine food intake. The animals were weighed weekly. Commencement of feeding the diets was staggered over $2 \mathrm{~d}$, with half the animals in each dietary group starting on each day.

The experimental diets contained $(\mathrm{g} / \mathrm{kg})$ : casein 198, starch 500, fat 200 , mineral mixture 40, vitamin mixture 20, solkafloc 40, L-methionine 2. MaxEPA oil (Seven Seas Ltd, Marfleet, Hull) was used to provide a source of EPA and DHA in the experimental diets and contained $100 \mathrm{mg}$ dodecyl gallate $/ \mathrm{kg}$ as antioxidant. The control diet contained no MaxEPA and the experimental diets contained 25, 50, 100 and $160 \mathrm{~g} \mathrm{MaxEPA} / \mathrm{kg}$. The proportion of total fat, saturated fatty acids and linoleic acid in each diet was kept constant and the experimental diets contained increasing amounts of EPA and DHA at the expense of monounsaturated fatty acids in the control diet. This was achieved by blending refined olive oil and safflower oil. The fatty acid composition of the diets was analysed by gas-liquid chromatography after methylation with sodium methoxide (Christie, 1973). The percentage contribution of fat to the energy intake of the animals per $\mathrm{d}$ was calculated using factors: $37.64 \mathrm{~kJ}(9 \mathrm{kcal}) / \mathrm{g}$ for fat, $16.73 \mathrm{~kJ}(4 \mathrm{kcal}) / \mathrm{g}$ for protein and $15.68 \mathrm{~kJ}(3.75 \mathrm{kcal}) / \mathrm{g}$ for carbohydrate.

\section{Popliteal lymph node assay}

Spleens were collected from both allogeneic (A-strain) and syngeneic $(\mathrm{CBA} \times \mathrm{CBA})$ mice fed on stock diet and sterile procedures were used throughout. The spleens were placed in separate plastic bottles each containing $5 \mathrm{ml}$ balanced salt solution (BSS; contained $(\mathrm{g} / \mathrm{l})$ : glucose 1, $\mathrm{KH}_{2} \mathrm{PO}_{4} \quad 0 \cdot 06, \mathrm{Na}_{2} \mathrm{HPO}_{4} \quad 0 \cdot 19, \mathrm{CaCl}_{2} .2 \mathrm{H}_{2} \mathrm{O} \quad 0 \cdot 186, \mathrm{KCl} 0 \cdot 8, \mathrm{NaCl} 8$, $\mathrm{MgSO}_{4} \cdot 7 \mathrm{H}_{2} \mathrm{O} 0.2, \mathrm{MgCl}_{2} \cdot 6 \mathrm{H}_{2} \mathrm{O} 0.2$, phenol red $0 \cdot 01$ ). The spleens were taken to a laminar flow cabinet and transferred to disposable plastic Petri dishes containing a small amount of BSS. Using two $2 \mathrm{ml}$ disposable syringes attached to $19 \mathrm{G}$ needles bent at right angles halfway along their length, the spleen cells were gently teased from their cases and the resulting cell suspension was filtered through a sterile nylon gauze $(80 \mu \mathrm{m})$ into a plastic tube. The Petri dish was rinsed with BSS and the rinsings transferred to the tube until the volume of cell suspension was $20 \mathrm{ml}$. The tube was capped and gently inverted in order to mix the cells and, using a sterile tip, $50 \mu \mathrm{l}$ of the suspension was removed for counting on a Coulter ZBI counter (Coulter Electronics Ltd, Dunstable, Beds.), after which the cells 
were centrifuged at $120 \mathrm{~g}$ for $15 \mathrm{~min}$ in a bench-top centrifuge. The packed cells were resuspended to a concentration of $1 \times 10^{8}$ cells $/ \mathrm{ml}$ after centrifugation. Typically, each spleen yielded $1-2 \times 10^{8}$ cells.

After dilution with the appropriate volume of BSS, spleen cells were taken up in a $1 \mathrm{ml}$ syringe attached to a $19 \mathrm{G}$ needle; the needle was then removed and replaced with a $25 \mathrm{G} \times 10 \mathrm{~mm}$ needle. Allogeneic cells were injected subcutaneously into the left hind foot pad and syngeneic cells into the right hind foot pad. The volume of cell suspension injected was $0.05 \mathrm{ml}$ and the syringes were continuously agitated in order to prevent the cells from settling out. The same volume of BSS was injected into the hind foot pads of two stockfed animals to ensure that there was no antigenic material in the BSS itself.

At $4 \mathrm{~d}$ after injection of spleen cells, $0.05 \mathrm{ml}$ Pontamine Sky Blue stain $(1 \mathrm{~g} / 100 \mathrm{ml}$ in aqueous solution; BDH Chemicals Ltd) was injected subcutaneously into the hind foot pads of each mouse in order to stain the popliteal lymph nodes and aid identification. The animals were killed by cervical dislocation immediately and the popliteal lymph nodes were exposed by an incision through the skin across the lumbar region of the back. By pulling the skin down, the lymph nodes were revealed on the dorsal side of the thigh, towards the knee joint. Using a pair of scissors and curved forceps, the nodes were removed very carefully, as they were extremely easy to burst, and laid on a filter paper. A scalpel with a small blade was then used to tease each node about the paper to remove excess fat and they were then weighed on a $50 \mathrm{mg}$ torsion balance (White and Co., Acton, London).

\section{Spleen leucocyte phospholipids}

The spleens were removed from each animal and weighed on an electronic laboratory balance. Spleens from two animals were pooled and placed in a Petri dish containing $3 \mathrm{ml}$ BSS. A spleen suspension was prepared as described for the mouse popliteal lymph node assay, giving a final volume of 5-6 $\mathrm{ml}$. Using a $19 \mathrm{G}$ needle and a $5 \mathrm{ml}$ disposable syringe, $3 \mathrm{ml}$ Histopaque 1119 (Sigma) was transferred to a plastic centrifuge tube and $3 \mathrm{ml}$ Histopaque 1077 (Sigma) was carefully layered over the top by running the liquid down the side of the tube to avoid mixing. The spleen cell suspension was layered over the Histopaque in the same manner and the tube was centrifuged at $1800 \mathrm{rev} . / \mathrm{min}$ for $30 \mathrm{~min}$ at room temperature. The top layer was discarded and the second layer, containing the leucocytes, was transferred to a glass centrifuge tube containing $8 \mathrm{ml}$ EDTA-saline $(9 \mathrm{~g}$ $\mathrm{NaCl} / 1$ ). The mixture was vortex mixed and centrifuged at $1500 \mathrm{rev} . / \mathrm{min}$ for $10 \mathrm{~min}$ at room temperature. The supernatant fraction was discarded and leucocyte phosphoacylglycerols extracted with 20 vol. of a mixture of chloroform-methanol $(1: 1, \mathrm{v} / \mathrm{v})$ containing $50 \mathrm{mg}$ butylated hydroxytoluene/1. The sample was loaded onto a straightphase silica Sep-Pak cartridge which had been pre-washed with $5 \mathrm{ml}$ methanol, then $5 \mathrm{ml}$ chloroform. Chloroform $(20 \mathrm{ml})$ was run through the column to extract non-phospholipid material, followed by $5 \mathrm{ml}$ chloroform-methanol $(49: 1, \mathrm{v} / \mathrm{v})$ to remove monoacylglycerols. Phospholipids were extracted by running $30 \mathrm{ml}$ methanol through the column and the eluant was collected and dried under $\mathrm{N}_{2}$. The lipid was redissolved in $0.3 \mathrm{ml}$ hexane and methylated with $2 \mathrm{M}$-sodium methoxide as described previously. The dry methyl esters were taken up in 50-100 $\mu 1$ hexane and analysed by gas-liquid chromatography.

Fatty acid methyl esters were separated on a $25 \mathrm{~m}$ fused silica capillary column coated with CpSil 88 (Chrompack UK Ltd, London). The splitter ratio was 50:1-100:1, $\mathrm{H}_{2}$ was used as the carrier gas at a linear velocity of $400 \mathrm{~mm} / \mathrm{s}$ and chromatographic peaks were integrated using a Shimadzu CR IB integrator. Methyl esters were identified by comparison with standards of known composition obtained from Sigma Chemical Company. Identification of fatty acids was confirmed by catalytic hydrogenation of methyl esters and re-analysis. 


\section{Statistics}

Data were analysed by one-way analysis of variance. Comparisons between individual groups were made using Duncan's multiple-range test. A paired sample $t$ test was used to test for differences between stimulated and unstimulated lymph nodes.

\section{RESULTS}

The proportion of dietary energy provided by the experimental diets is shown in Table 1 . The proportion of dietary energy provided and linoleic acid and saturated fatty acids in the diets was approximately constant, and the proportion of EPA and DHA increased as the proportion of mono-unsaturated fatty acids decreased. Food intakes and growth rates did not differ significantly between treatments.

Spleen weights did not differ significantly with dietary treatment; values for control, 25 , 50,100 and $160 \mathrm{~g} / \mathrm{kg}$ fish oil were $58,63,61,60$ and $63 \mathrm{mg}$ respectively and the pooled SD was $5.4 \mathrm{mg}$. Major changes were apparent in spleen leucocyte phospholipid fatty acid composition, even at lower intakes of MaxEPA (Table 2). The proportions of palmitic (16:0) and palmitoleic (16:1) acid were higher in the control animals compared with the MaxEPA groups, even though the intake of $16: 1$ was greater in the animals receiving MaxEPA. The proportion of linoleic acid $(18: 2 n-6)$ was higher in the group receiving the highest intake of MaxEPA compared with the control, despite the dietary intake of linoleic acid being well controlled. Despite the marked difference in dietary intake of oleic acid (18:1n-9) between groups, the proportion of this fatty acid in spleen leucocyte phospholipids did not change.

The percentage of EPA in the phospholipid fraction rose in a dose-dependent manner from 0.14 of the fatty acids in the controls to 9.4 in the $160 \mathrm{~g} \mathrm{MaxEPA} / \mathrm{kg}$ diet group. This change was accompanied by a corresponding decrease in the percentage of arachidonic acid $(20: 4 n-6)$ from $22 \cdot 8$ to $7 \cdot 3$. In contrast, the percentage of DHA in the phospholipid fraction rose from 4.8 in the control animals to approximately 12 in the animals fed on $25 \mathrm{~g}$ MaxEPA $/ \mathrm{kg}$ diet but showed no further increase with higher intakes of fish oil.

The popliteal lymph nodes of the stock-fed animals injected with BSS were, as expected, significantly smaller (left foot 0.9 (SE 0.11$) \mathrm{mg}$, right foot 1.0 (SE 0.14$) \mathrm{mg}$, difference 0.1 (SE 0.02)) than those of the other animals $(P<0.01)$ as they had not been stimulated with spleen cells and, therefore, did not enlarge. The right foot which was injected with syngeneic cells was approximately 2.5 times heavier than in the BSS-treated animals $(P<0.01)$, whereas those feet injected with allogeneic cells were about five times heavier than in animals injected with BSS $(P<0.01)$; the difference between stimulated and unstimulated lymph nodes was statistically significant in all groups $(P<0 \cdot 01)$. Spleen weights were not affected by the injection of cells. The effect of the different levels of MaxEPA in the diets on the $\mathrm{H} v . \mathrm{G}$ response is shown (Table 3). The highest intakes of EPA and DHA, i.e. the diet containing $160 \mathrm{~g}$ MaxEPA/kg, significantly suppressed the CMI response, but lower intakes had no effect.

\section{DISCUSSION}

There is a considerable body of evidence demonstrating that dietary fish oils can influence inflammatory reactions associated with autoimmune disorders, both in experimental animals and man (Walton et al. 1991). A few attempts have been made previously to examine the influence of dietary fish oils on CMI. Most of the studies have looked at the influence of fish oil-supplemented diets on autoimmune diseases rather than the CMI response. Immune response in post-burn guinea-pigs given different levels of MaxEPA in enteral formulas was examined by Trocki et al. (1987). It was argued that degree of ear swelling $24 \mathrm{~h}$ after dinitrofluorobenzene application was a direct measure of CMI response. 
Table 1. Percentage dietary energy provided by the experimental diets containing different levels of fish oil

\begin{tabular}{|c|c|c|c|c|c|}
\hline Fish oil $(\mathrm{g} / \mathrm{kg}$ diet $) \ldots$ & 0 & 25 & 50 & 100 & 160 \\
\hline Saturated fatty acids & $9 \cdot 2$ & $9 \cdot 3$ & $9 \cdot 5$ & 9.5 & $10 \cdot 0$ \\
\hline Mono-unsaturated fatty acids & $24 \cdot 2$ & $23 \cdot 1$ & $20 \cdot 6$ & 15.9 & 10.7 \\
\hline Linoleic acid $(18: 2 n-6)$ & $4 \cdot 8$ & $4 \cdot 7$ & 4.8 & $4 \cdot 4$ & 4.7 \\
\hline Eicosapentaenoic acid $(20: 5 n-3)$ & 0 & 0.8 & 1.7 & 36 & 5.5 \\
\hline Docosahexaenoic acid $(22: 6 n-3)$ & 0 & 0.6 & $1-2$ & $2 \cdot 4$ & 3.6 \\
\hline
\end{tabular}

Table 2. Influence of experimental diets containing different levels of fish oil on spleen leucocyte phospholipid composition (mol/100 mol total fatty acids) in mice

(Mean values for four pairs of animals per group)

\begin{tabular}{|c|c|c|c|c|c|c|c|c|}
\hline Fatty acid & Fish oil $(\mathrm{g} / \mathrm{kg} \text { diet })^{*}$ & 0 & 25 & 50 & 100 & 160 & $\begin{array}{l}\text { Pooled } \\
\text { SD }\end{array}$ & $\begin{array}{c}\text { Statistical } \\
\text { significance : } P\end{array}$ \\
\hline $16: 0$ & & $19 \cdot 7^{\mathrm{a}}$ & $15 \cdot 1^{\mathrm{b}}$ & $15 \cdot 5^{\mathrm{h}}$ & $14 \cdot 8^{\mathrm{b}}$ & $15 \cdot 1^{\mathrm{b}}$ & 1.99 & $0 \cdot 016$ \\
\hline $16: 1$ & & $3 \cdot 4^{\mathrm{a}}$ & $1 \cdot 4^{\mathrm{b}}$ & $1 \cdot 4^{\mathrm{b}}$ & $0 \cdot 8^{b}$ & $1 \cdot 0^{3}$ & $1 \cdot 22$ & 0.067 \\
\hline $18: 0$ & & $13 \cdot 1$ & 12.9 & $12 \cdot 9$ & $12 \cdot 6$ & $12 \cdot 3$ & 0.87 & 0.739 \\
\hline $18: 1$ & & $16 \cdot 8$ & $14 \cdot 7$ & $16 \cdot 8$ & $18 \cdot 2$ & $17-7$ & $3 \cdot 35$ & 0.638 \\
\hline $18: 2 n-6$ & & $5 \cdot 8^{\mathrm{aht}}$ & $7 \cdot 2^{b}$ & $7 \cdot 3^{\mathrm{b}}$ & $7 \cdot 2^{b}$ & $7 \cdot 7^{13 x}$ & $1 \cdot 12$ & 0.067 \\
\hline $20: 3 n-6$ & & $1 \cdot 1^{\mathrm{a} b}$ & $1 \cdot 1^{\mathrm{b}}$ & $1 \cdot 4^{a b r}$ & $0.9^{\mathrm{a}}$ & $1 \cdot 1^{\mathrm{ith}}$ & $0 \cdot 36$ & 0.076 \\
\hline $20: 4 n-6$ & & $20 \cdot 8^{a}$ & $13 \cdot 4^{\mathrm{b}}$ & $9 \cdot 6^{\circ}$ & $7 \cdot 8^{\mathrm{c}}$ & $7 \cdot 3^{c}$ & 1.57 & 0.000 \\
\hline $20: 5 n-3$ & & $0 \cdot 14^{\mathrm{a}}$ & $3 \cdot 8^{\mathrm{b}}$ & $7 \cdot 2^{\circ}$ & $8 \cdot 5^{a}$ & $9 \cdot 4^{\prime \prime}$ & $0 \cdot 84$ & 0.000 \\
\hline $22: 4 n-6$ & & $4 \cdot 1^{a}$ & $2 \cdot 1^{b}$ & $1 \cdot 2^{\mathrm{b}}$ & $1 \cdot 4^{\mathrm{h}}$ & $0 \cdot 8^{b}$ & 0.94 & 0.0016 \\
\hline $22: 5 n-3$ & & $1.7^{\mathrm{a}}$ & $4 \cdot 2^{b}$ & $4.9^{b}$ & $5 \cdot 1^{b}$ & $5 \cdot 0^{\mathrm{b}}$ & 0.845 & 0.014 \\
\hline $22: 6 n-3$ & & $5 \cdot 1^{\mathrm{a}}$ & $12 \cdot 1^{\mathrm{b}}$ & $12 \cdot 2^{\mathrm{b}}$ & $12 \cdot 8^{b}$ & $12 \cdot 9^{b}$ & 1.49 & 0.000 \\
\hline
\end{tabular}

u.,, ce, 1 Mean values with different superscript letters were significantly different $(P<0.05)$.

* For details of diets, see Table 1 and p. 424.

Table 3. Influence of diets containing different levels of fish oil on cell-mediated immunity in mice

(Mean values for eight animals per group)

\begin{tabular}{|c|c|c|c|c|c|c|c|}
\hline \multirow[b]{3}{*}{ Fish oil (g/kg diet $) \dagger$} & \multicolumn{7}{|c|}{ Lymph node weight (mg) } \\
\hline & \multicolumn{2}{|c|}{ Stimulated } & \multicolumn{2}{|c|}{ Unstimulated } & \multicolumn{2}{|c|}{ Difference } & \multirow{2}{*}{$\begin{array}{c}\text { Statistical } \\
\text { significance } \\
\text { of difference: } P\end{array}$} \\
\hline & Mean & SEM & Mean & SEM & Mean & SEM & \\
\hline 0 & 4.94 & 0.41 & $2 \cdot 56$ & $0 \cdot 21$ & $2 \cdot 38$ & 020 & 0.01 \\
\hline 25 & $5 \cdot 25$ & 0.50 & $2 \cdot 33$ & 0.25 & $3 \cdot 10$ & 0.70 & 001 \\
\hline 50 & $4 \cdot 68$ & 0.41 & $2 \cdot 26$ & $0 \cdot 30$ & $2 \cdot 44$ & $0 \cdot 44$ & 0.01 \\
\hline 100 & $4 \cdot 86$ & 0.58 & $2 \cdot 50$ & $0 \cdot 30$ & $2 \cdot 50$ & 0.50 & 0.01 \\
\hline 160 & 3.67 & 0.23 & $2 \cdot 63$ & $0 \cdot 36$ & $1.05^{*}$ & $0 \cdot 22$ & 0.01 \\
\hline Pooled SD & $1 \cdot 217$ & & 0.845 & & $1 \cdot 127$ & & \\
\hline $\begin{array}{l}\text { Statistical significance } \\
\text { between groups: } P\end{array}$ & $0 \cdot 116$ & & $0 \cdot 848$ & & 0.025 & & \\
\hline
\end{tabular}

Mean value was significantly different from those of other groups: ${ }^{*} P<0.05$.

$\dagger$ For details of diets, see Table 1 and p. 424. 
No suppression of CMI was demonstrated with fish oil, even at the highest intake $(50 \%$ of the energy intake as MaxEPA).

Prickett et al. $(1981,1983)$ compared the effects of diets containing menhaden oil or beef tallow $(250 \mathrm{~g} / \mathrm{kg})$ as the lipid source in the diet on mortality in NZB/NZWF mice with autoimmune nephritis. Animals fed on fish oil exhibited dose-dependent protection from mortality, most marked at $110-250 \mathrm{~g} / \mathrm{kg}$ diet. Similar experiments by Robinson et al. (1987) using diets containing ethyl EPA and DHA (90\%) confirmed the protective effect of these fatty acids. This animal model is one of humoral-mediated immunity rather than CMI. However, in many of these studies the animals were not fed on well-defined diets. In some cases the experimental diets differed from the control diets in several aspects, notably with regard to linoleic acid and saturated fatty acid content. Also, none of the studies has made a systematic effort to control food intake. This is of importance as there is evidence suggesting CMI is influenced by energy intake (Safai-Kutti et al. 1980). In the present study precautions were taken to control the intakes of linoleic and saturated fatty acids and to ensure that food intakes were similar. Mono-unsaturated fatty acids were replaced with polyunsaturated fatty acids in the experimental diets as it had been shown previously that acute administration of ethyl oleate had no influence on CMI in this model (Sanders et al. 1985).

CMI has traditionally been studied using skin-allografts. The mouse popliteal lymph node assay was developed as an alternative to this method and has been well validated. Moreoever, it has been shown to be affected by linoleic acid intake (Mertin \& Stackpoole, 1981). Mertin (1983) reported that treatment with a single dose of MaxEPA given orally suppressed H v. G in mice using this animal model of CMI. Sanders et al. (1985) confirmed this observation that acute administration of MaxEPA or the ethyl ester of EPA inhibited $\mathrm{CMI}$ in the mouse using $\mathrm{CBA} \times \mathrm{CBA}$ injected with $\mathrm{CBA} \times \mathrm{B} 10$-release cells. However, feeding MaxEPA at approximately $40 \mathrm{~g} / \mathrm{kg}$ diet for 4 weeks did not suppress the CMI response, although spleen lipids were markedly altered. The results of the present study confirm this observation but show that high intakes are immunosuppressive. The mouse is the favoured animal model for immunological studies as the immunological characteristics of the various strains have been extensively studied. We found it necessary to carry out experiments in animals of this age because pilot studies showed that the $\mathrm{H} v$. G response was smaller in older animals. Moreoever, A-strain mice were used as a source of allogeneic cells, as this supplies a greater histocompatibility barrier.

The present study shows that only very high intakes of EPA and DHA are immunosuppressive in the $\mathrm{H} v$. G model. The intakes that were found to be immunosuppressive provided approximately $10 \%$ of the dietary energy intake. This amount is considerably greater than that found in human diets. For example, these fatty acids provided approximately 5-6\% of the energy intake in Greenland Eskimos (Bang \& Dyerberg, 1980). As the proportion of DHA plateaued at low intakes it seems unlikely that this fatty acid was responsible for the suppression of CMI. It has been argued that arachidonic acid from the phosphatidyl inositol pool is the main precursor for prostaglandin formation (Sprecher et al. 1987) and that it is only when this pool is depleted that functional differences occur. The concentration of arachidonic acid in phosphatidyl inositol was not measured. However, the difference between the spleen leucocyte phospholipid composition in the groups fed on 100 and $160 \mathrm{~g} / \mathrm{kg}$ was relatively small. Thus, it is unlikely that differences in membrane composition can explain the immunosuppressive effect of the highest intake of fish oil. It is possible that other consitutents of the fish oil EPA and DHA may be responsible for this effect. Lipid peroxides might appear to be a candidate. However, other workers have failed to show any impaired immune response in animals with yellow fat disease (Danse et al. 1979). An 
alternative explanation may relate to the proportion of EPA in the free fatty acid fraction. Acute feeding studies show suppression of the $\mathrm{H} v . \mathrm{G}$ response following a single dose of EPA; this could be related to the increase in EPA in the free fatty acid fraction following absorption. Animals fed on moderate amounts of fish oil do not accumulate large amounts of EPA in adipose tissue (Roshanai \& Sanders, 1985) whereas those fed on large amounts do (Brockerhoff et al. 1967). The immunosuppressive effect of high intakes of fish oil could, therefore, be related to a higher proportion of EPA in free fatty acids arising from lipolysis of fat stores.

The findings of the present study do not support the contention that the chronic consumption of moderate amounts of fish oil in the diet will result in suppression of the $H$ v. G response.

\section{REFERENCES}

Bang, H. \& Dyerberg, J. (1980). Lipid metabolism in Greenland Eskimos. Advances in Nutrition Research 3, 1-40.

Brockerhoff, H., Hoyle, R. J. \& Hwang, P. C. (1967). Incorporation of fatty acids of marine origin into triglycerides and phospholipids of mammals. Biochimica et Biophysica Acta 144, 541-548.

Christie, W. W. (1973). Lipid Analysis. Oxford: Pergamon Press.

Danse, L. H. J. C., Stolwijk, J. \& Verschuren, P. M. (1979). Fish oil-induced yellow fat disease in rats. Veterinary Pathology 16, 593-603.

Hinds, A. \& Sanders, T. A. B. (1986). Effect of increasing levels of dietary eicosapentaenoic (20:5n-3) and docosahexaenoic $(22: 6 n-3)$ acids on lymphocyte phospholipid composition and cell-mediated immunity in the mouse. Proceedings of the Nutrition Society 46, 87 A.

Mertin, J. (1983). Omega-6 and omega-3 polyunsaturates and the immune system. British Journal of Clinical Practice 38, Suppl. 5, 111-114.

Mertin, J. \& Stackpoole, A. (1981). Prostaglandin precursors and cell-mediated immune response. Cellular Immunology 62, 293-300.

Mertin, J. \& Stackpoole, A. (1983). Immune sera direct against prostaglandin E inhibit cell-mediated immune responses. Transplantation Proceedings 15, 427-428.

Prickett, J., Robinson, D. \& Steinberg, A. (1981). Dietary enrichment with the polyunsaturated fatty acid eicosapentaenoic acid prevents proteinuria and prolongs survival in NZB $\times \mathrm{NZF}^{\mathbf{1}}$ mice. Journal of Clinical Investigation 68, 55-59.

Prickett, J., Robinson, D. \& Steinberg, A. (1983). Effects of dietary enrichment with eicosapentaenoic acid on autoimmune nephritis in female $\mathrm{NZB} \times \mathrm{NZWF}_{1}$ mice. Arthritis and Rheumatism 26, $133-139$.

Robinson, D., Tateno, S., Patel, B. \& Hirai, A. (1987). The effects of dietary marine lipids on autoimmune disease. In Proceedings of the AOCS Short Course on Polyunsaturated Fatty Acids and Eicosanoids, pp. $139-147$ [W. E. M. Lands, editor]. Champaign, Illinois: American Oil Chemists' Society.

Rolstad, B. (1976). The host component of the graft-versus-host reaction: a study of the popliteal lymph node reaction in the rat. Transplantation 21, 117-123.

Roshanai, F. \& Sanders, T. A. B. (1985). Influence of different supplements of $n-3$ polyunsaturated fatty acids on blood and tissue lipids in rats receiving high intakes of linoleic acid. Annals of Nutrition and Metabolism 29, $189-196$.

Safai-Kutti, S., Fernandes, G., Wang, Y., Safai, B., Good, R. A. \& Day, N. K. (1980). Reduction of circulating immune complexes by calorie restriction in $(\mathrm{NSB} / \mathrm{NZW}) \mathrm{F}_{1}$ mice. Clinical Immunology and Immunopathology 15, 293-300.

Sanders, T. A. B. (1988). Trans and essential fatty acids in nutrition. Nutrition Research Reviews 1, 57-78.

Sanders, T. A. B., Grahame, M. \& Mistry, M. (1985). Influence of dietary eicosapentaenoic (20:5n-3) and docosapentaenoic $(22: 6 n-3)$ acids on cell-mediated immunity in the mouse. Proceedings of the Nutrition Society 44, 6A.

Sprecher, H., Voss, A. C., Careaga, M. \& Hadjiagapiou, C. (1987). Interrelationships between polyunsaturated fatty acid and membrane lipid synthesis. In Proceedings of the AOCS Short Course on Polyunsaturated Fatty Acids and Eicosanoids, pp. $154-168$ [W. E. M. Lands, editor]. Champaign, Illinois: American Oil Chemists' Society.

Trocki, O., Heyd, T., Waymak, J. \& Alexander, J. (1987). Effects of fish oil on post-burn metabolism and immunity. Journal of Parenteral and Enteral Nutrition 2, 521-528.

Twist, V. \& Barnes, R. (1973). Popliteal lymph node weight gain assay for graft-versus-host reactivity in mice. Transplantation 15, 182-185.

Walton, A. J., Snaith, M. L., Locniskar, M., Cumberland, A. G., Morrow, W. J. \& Isenberg, D. A. (1991). Dietary fish oil and the severity of symptoms in patients with systemic lupus erythematosus. Annals of Rheumatic Diseases 50, 463-466.

Printed in Great Britain 